\title{
Modeling Dubai City Artificial Channel
}

\author{
Mohamed Elhakeem and Mohamed El Amrousi \\ Abu Dhabi University, Abu Dhabi, P.O. Box 59911, UAE
}

\begin{abstract}
Dubai's new channel further enhances the urban-scape of the city offering new waterfront developments, transportation venues and diversified panoramas to the city. This paper performs a study to simulate the flow field in the proposed Dubai artificial channel using a 2D hydrodynamic model. The model predicts the flow depth and velocity in the channel, lagoons and bends. The model predictions show that the velocity is higher in the channel sections compared to the lagoons and bends sections. On the other hand, the water depth is lower in the channel sections compared to the lagoons and bends sections. Nonetheless, the velocities in the channel are within the accepted range that prevents boundary erosion and sediment deposition.
\end{abstract}

\section{Introduction}

Like several modern Arabian Gulf cities, Dubai is interested in creating landmarks to attract investors through display of its ability to create architectural spectacles that can be part of the World Genius Record. Among these landmarks are the artificial islands of Palm Jebel Ali and the Palm Jumeirah that shape Dubai new shoreline (Figure 1). The Dubai Palms increased the emirate's shoreline by a total of $520 \mathrm{~km}$ promoted the establishment of 100 s luxury hotels, residential beachside villas and apartments, marinas, water theme parks, restaurants, shopping malls, sports facilities and health spas.

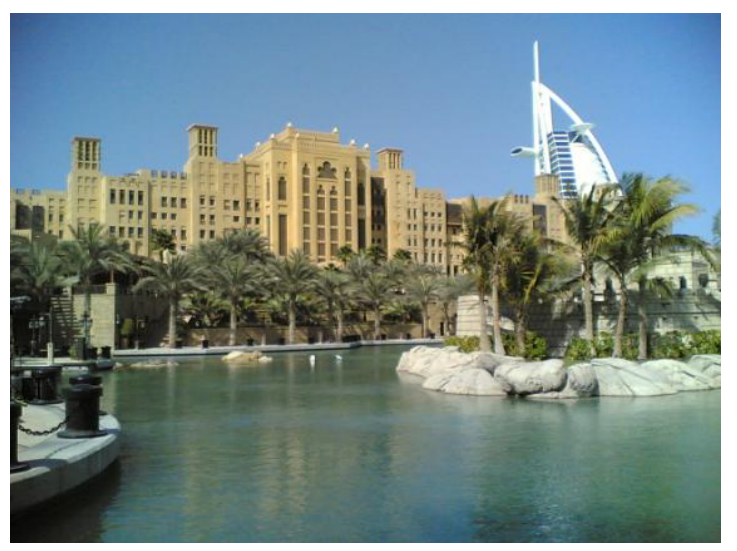

Figure 1. Jumeirah hotel and residences around its artificial canals and lagoons.

Dubai's new waterfront developments in the form of artificial Islands, lagoons and water channels are all part of branding Dubai as part of the emerging network of modern global cities such as Kuala Lumpur and Singapore. The marketing power of Dubai as a brand name and lifestyle by EMAAR and NAKHEEL, and the instability created by the Arab Spring in cities like Cairo, Damascus that were shaped by multi-layers of history and collective memories have contributed further to Dubai as a city spaces of hope for the future [1].

The investment to create a main water channel from the boundaries of Diera onwards manifests the constant desire of Dubai authority to create new real estate properties along this channel as part of Dubai developments. The project includes digging of the water channel, lining of its boundaries and constructing a number of bridges to cross the channel. The project includes also the construction of 12 marine transit stations to enable convenient and effective watertransportation to link Dubai's several man made islands with the downtown. According to the Roads and Transport Authority (RTA), the channel will offer new means of public transportation for one million of Dubai residents and will become part of the mass transit network of Dubai [2]. The new channel (Figure 2) which is $2.8 \mathrm{~km}$ long, $80 \mathrm{~m}$ wide and $6 \mathrm{~m}$ deep, will connect the historic Khor Dubai to Al-Safwa shorefront passing through downtown of Dubai near Burj Khalifa area and its surrounding artificial lagoons [3]. The channel will receive its water from the sea and delivers it back to the sea. The new channel manifests how Dubai is constantly seeking to enhance the image and urban visibility of the city. Dubai's high-end shorefront developments reveal the essence of the presence of water not merely as a landscape feature but ideologically connecting Dubai's past as a pearl fishermen port city to a modern urban enclave of spectacle and richness.

Due to the lagoons and bends effects, the flow field in the proposed Dubai artificial channel would be of complex nature. This can be investigated by either physical models using experimental flumes or numerical 
models using computational fluid dynamics (CFD) methods. Numerical models are cheaper and offer more flexibility compared to physical models when modifications are needed to the channel shape. In addition, CFD simulations can provide detailed information of the flow field in the channel and lagoons under various hydraulic conditions [4]. The main objective of this study is to investigate the flow pattern in Dubai Channel using a 2D water surface model. The 2D water surface model can help in planning the landscape of the channel by minimizing the scour or sediment deposition at the channel entrance and exit and minimizing the eddy effects in the bends sections.

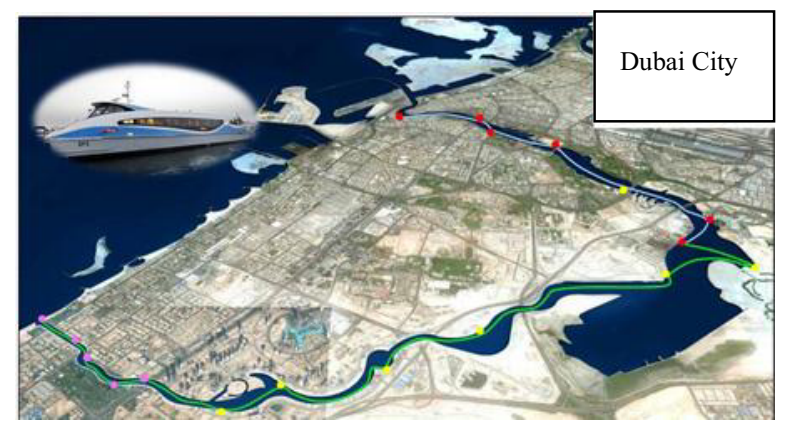

Figure 2. Dubai water channel project [3].

\section{Methodology}

Due to the complex landscape geometry of the Dubai Channel (Figure 3), the 2D Finite Element Surface Water Modeling System (FESWMS) is used to investigate the flow pattern in the channel. FESWMS is part of the commercially available Surface water Modeling System (SMS) package version 10.2 Graphical Interface that combines a series of hydrodynamic/ sediment codes [5]. The model was successfully used to simulate flow in stream with bends and lagoons similar to Dubai Channel [6].

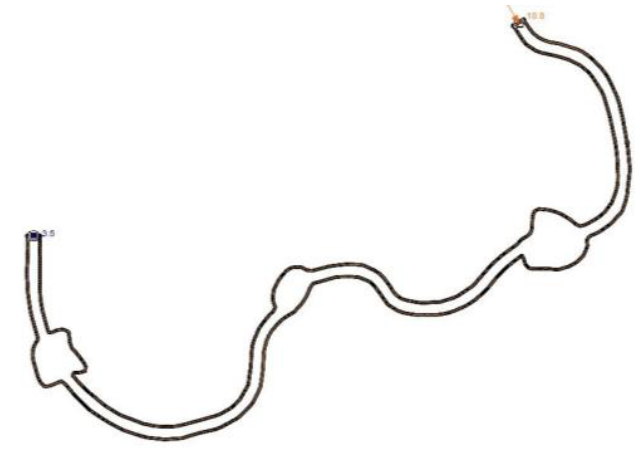

Figure 3. Proposed Dubai water channel layout.

FESWMS solves the differential forms of the continuity and the momentum equations in the stream wise and transverse directions using the Galerkin method of weighted residuals, providing water depth and depthaveraged velocity magnitude in $x$ and $y$ directions at each node in the grid [7]. The governing equations are written in the conservative form hence, the momentum is conserved along the streamline and the model is capable of capturing shock effects [4]. The conservative form was chosen because of its robustness in solving critical and transcritical flow fields under both low and high flow conditions by allowing dry-elements to exist within the computational mesh [4].

FESWMS solves the following equations simultaneously:

$$
\begin{gathered}
\frac{\partial z_{w}}{\partial t}+\frac{\partial q_{1}}{\partial x}+\frac{\partial q_{2}}{\partial y}-q_{m}=0 \\
\frac{\partial q_{1}}{\partial t}+\frac{\partial}{\partial x}\left(\frac{q_{1}^{2}}{d}+\frac{1}{2} g d^{2}\right)+\frac{\partial}{\partial y}\left(\frac{q_{1} q_{2}}{d}\right)+g d \frac{d z_{b}}{\partial x} \\
+g n^{2} \frac{q_{1} \sqrt{q_{1}^{2}+q_{2}^{2}}}{d^{7 / 3}} \sqrt{1+\left(\frac{\partial z_{b}}{\partial x}\right)^{2}+\left(\frac{\partial z_{b}}{\partial y}\right)^{2}} \\
-2 d \varepsilon_{x x} \frac{\partial^{2} \bar{u}}{\partial x^{2}-\varepsilon_{x y}} \frac{\partial}{\partial y}\left(\frac{\partial \bar{u}}{\partial x}+\frac{\partial \bar{v}}{\partial y}\right)=0 \\
\frac{\partial q_{2}}{\partial t}+\frac{\partial}{\partial x}\left(\frac{q_{1} q_{2}}{d}\right)+\frac{\partial}{\partial y}\left(\frac{q_{2}^{2}}{d}+\frac{1}{2} g d^{2}\right)+g d \frac{d z_{b}}{\partial y} \\
+g n^{2} \frac{q_{2} \sqrt{q_{1}^{2}+q_{2}^{2}}}{d^{7 / 3}} \sqrt{1+\left(\frac{\partial z_{b}}{\partial x}\right)^{2}+\left(\frac{\partial z_{b}}{\partial y}\right)^{2}} \\
-2 d \varepsilon_{y y} \frac{\partial^{2} \bar{v}}{\partial y^{2}-\varepsilon_{y x}} \frac{\partial}{\partial x}\left(\frac{\partial \bar{u}}{\partial x}+\frac{\partial \bar{v}}{\partial y}\right)=0
\end{gathered}
$$

where Eq. (1) is the continuity and Eqs. (2) and (3) are the momentum equations in $x$ and $y$ directions, respectively. In the equations, $t$ is time (s), $d$ is water depth $(\mathrm{m}), \rho$ is water density $\left(\mathrm{kg} / \mathrm{m}^{3}\right), g$ is the acceleration due to gravity $\left(\mathrm{m} / \mathrm{s}^{2}\right), n$ is Manning's coefficient of roughness, $z_{w}$ and $z_{b}$ are water surface elevation and bed elevation above certain datum (m), $q_{1}$ and $q_{2}$ are the unit discharge fluxes $\left(\mathrm{m}^{2} / \mathrm{s}\right)$ defined as $\bar{u}_{d}$ and $\bar{v}_{d}$, respectively, $\bar{u}$ and $\bar{v}(\mathrm{~m} / \mathrm{s})$ are the depthaveraged velocities of an element in the stream wise and transverse directions, respectively, $q_{\mathrm{m}}$ is the resultant inflow or outflow from that element $(\mathrm{m} / \mathrm{s}), v_{x x}$ and $v_{y y}$ are the normal components of the eddy viscosity $\left(\mathrm{m}^{2} / \mathrm{s}\right)$ in the $x$ and $y$ directions, respectively, and $v_{x y}$ and $v_{y x}$ are the shear components of the eddy viscosity $\left(\mathrm{m}^{2} / \mathrm{s}\right)$ applied to the $x-y$ plane.

FESWMS inputs are the Manning's coefficient of roughness $n$, and the eddy viscosity $v$. Model inputs must be assigned correctly to represent the physical processes occurring in the modeled reach and to produce accurate model predictions. Manning's $n$ is an empirical coefficient that accounts for the total flow resistance caused by flow interaction with the boundary [7]. FESWMS utilizes Manning's $n$ to account for momentum loss due to bed-shear, which may vary significantly in a stream reach in accordance to bed-bathymetry and roughness. The second input variable used by FESWMS 
is the eddy viscosity $v$. Eddy viscosity accounts for flow resistance due to the internal shear stresses, or the Reynolds' stresses of the fluid incorporating the added energy dissipation due to turbulence in the flow [8]. Therefore, eddy viscosity is not a physical property of the fluid, but rather a turbulent characteristic of the flow. For isotropic flows in prismatic channels, a single eddy viscosity value is sufficient to describe the turbulence flow characteristics within the modeled reach.

\section{Results}

The appropriate size of the mesh elements can be estimated from the mesh Peclet number criterion, defined as the ratio of advection to diffusion occurring in an element [9]. This can be expressed mathematically as:

$$
P_{e}=U R / v_{t}
$$

where $U(\mathrm{~m} / \mathrm{s})$ is the resultant depth-averaged velocity of the element $\left(U=\sqrt{\bar{u}^{2}+\bar{v}^{2}}\right), v_{t}$ is the eddy viscosity $\left(\mathrm{m}^{2} / \mathrm{s}\right)$ in the flow direction $\left(v_{t}=\sqrt{\varepsilon_{x x}^{2}+\varepsilon_{y y}^{2}}\right)$, and $R$ is the maximum distance between two nodes on the element (m).

The mesh Peclet equation shows that $U$ and $v_{t}$ determine the ideal element size $R$ and thus the minimum eddy length that can be resolved. However, the element size is also a function of local bathymetry including bed roughness, and tailoring a mesh grid design to ensure a constant mesh Peclet number throughout the reach is laborious and unreasonable. It is therefore sufficient to keep the mesh Peclet number within the recommended range for all the elements in the computational mesh. Prior studies using FESWMS [10, 11] recommended a mesh Peclet number between 10 and 40 to ensure that: 1) momentum is dominated by advection; 2) eddy viscosity maintains flow consistency and prevents oscillation; and 3) proper amount of energy loss due to dispersion takes place in each element to account for microeddies, which are too small to be resolved in the mesh (i.e., those eddies that are smaller than the local element size). Keeping the mesh Peclet criterion within the recommended range and resolving for the ideal element size $R$ minimizes the errors that can result from the spatial resolution of the computational mesh [12, 13, 14]. Figure 4 shows the size of the generated mesh elements in the channel, which satisfy the range of the recommended mesh Peclet number.

Although FESWMS possesses the capability of spatially distributing both Manning's $n$ and eddy viscosity in the computational mesh, it is common to use averaged values for Manning's $n$ and eddy viscosity. In prismatic channels under uniform flow conditions, an average eddy viscosity value can be assigned to the study reach as a function of depth and bed slope [15, 16]. In this study, it is assumed that the channel has a rectangular cross-section with a width of $80 \mathrm{~m}$ and variable width at the lagoon sections. The model inputs are: the channel bathymetry, Manning's coefficient $n=0.02$, eddy viscosity $v=0.01 \mathrm{~m}^{2} / \mathrm{s}$, flow rate at the upstream $Q=500$ $\mathrm{m}^{3} / \mathrm{s}$, water surface elevation at the downstream $y=5.8 \mathrm{~m}$. Figures 5 and 6 show the water depth in meter and the water velocity, respectively in the simulated channel. The minimum and maximum depths in the channel were 5.2 and $6.0 \mathrm{~m}$, respectively. Velocity is the range of 0.3 to 1.2 $\mathrm{m} / \mathrm{s}$ with higher values in the channel sections and lower values in the lagoons sections. The model predictions show that the water depth is lower in the channel sections compared to the lagoons and bends sections. On the other hand, the velocity is higher in the channel sections compared to the lagoons and bends sections. Figure 7 shows the velocity vectors in the eastside lagoon. It is clear from the figure that the model was able to mimic the expected flow field in the lagoon.

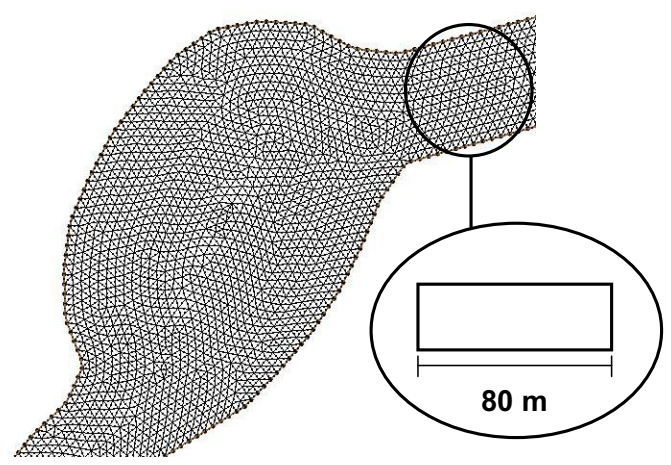

Figure 4. The size of the generated mesh elements for the middle lagoon section.

Recommended minimum velocity in rigid boundary channels should be in the range of $0.6 \mathrm{~m} / \mathrm{s}$ such that sediment is not deposited, aquatic growth is inhibited, and sulfide formation does not occur, while recommended maximum velocity should be in the range of $6.0 \mathrm{~m} / \mathrm{s}$ to avoid boundary erosion [17]. In addition, the Froude number $\left(F_{r}=U / \sqrt{g\left(z_{w}-z_{b}\right)}\right)$ should be in the range of 0.3 so that the water surface does not become rough, especially downstream of obstructions and in bends. From the model simulation, it can be seen that the velocities as well the Froude number in the Dubai artificial channel are within the accepted range recommended for rigid boundary channels.

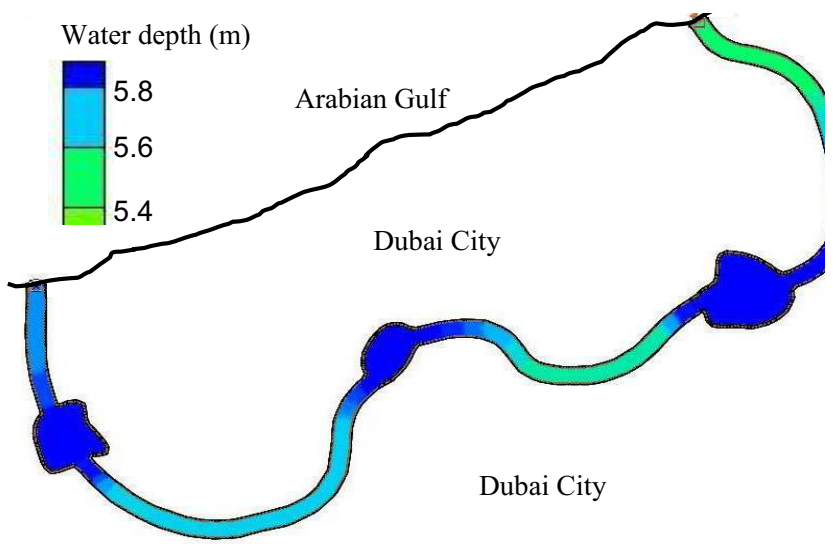

Figure 5. Simulation of the water depth in the Dubai city channel. 


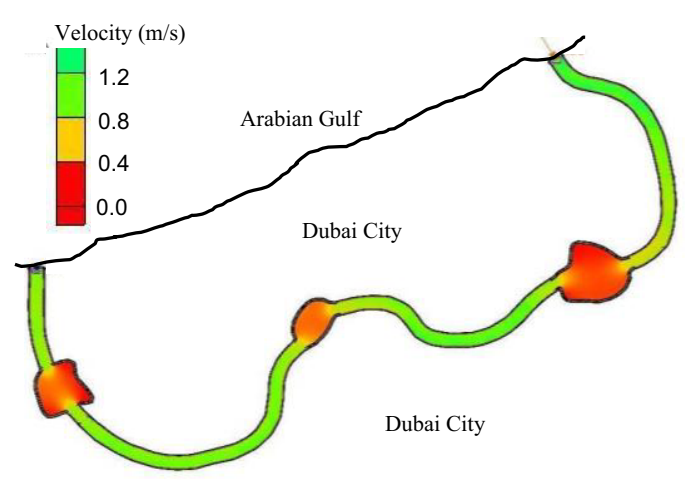

Figure 6. Simulation of the flow velocity in the Dubai city channel.

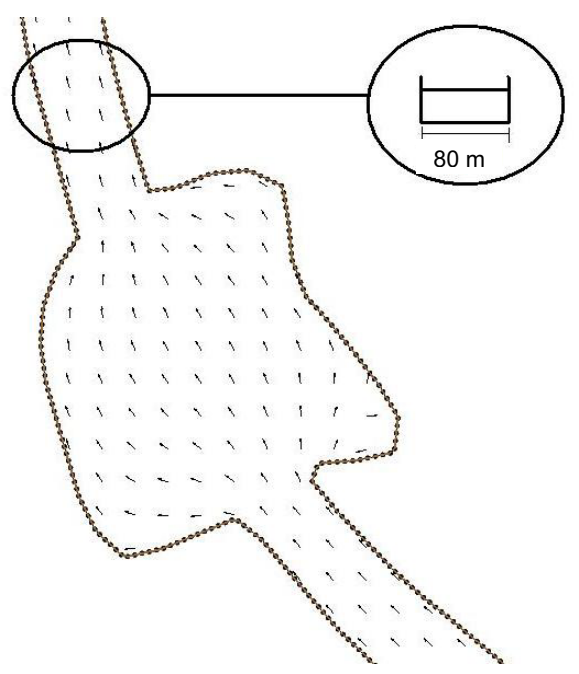

Figure 7. Flow direction in the eastside lagoon of the channel.

\section{Summary}

Dubai's new channel further enhances the urban-scape of the city offering new waterfront developments, transportation venues and diversified panoramas to the city. A study was performed to simulate the flow field in the proposed Dubai artificial channel using a 2D hydrodynamic model. The model predicts the flow depth and velocity in the channel, lagoons and bends sections. The model predictions show that the velocity is higher in the channel sections compared to the lagoons and bends sections. On the other hand, the water depth is lower in the channel sections compared to the lagoons and bends sections. Nonetheless, the velocities in the channel are within the accepted range that prevents boundary erosion and sediment deposition. In addition, the Froude number was in the range that averts the water surface from becoming rough, especially in the bends sections.

\section{References}

1. M. El Amrousi, P. Caratelli, S. Shakour, ACSA/AIK International Conference 2014: Open Cities, Seoul Korea, (2014)

2. Business Bay, Water Canal marine stations, Emirates 24/7, (August 15, 2015)

3. Business Bay canal extension set to energize Dubai's landscape, McClatchy-Tribune Business News, Washington, (October 2012)

4. H.M. Chaudhry, Open Channel Flow, Springer, New York, (2008)

5. D. Froelich, User's Manual for FESWMS Flo2DH: Two-Dimensional Depth-Averaged Flow and Sediment Transport Model, Release 3, (2002)

6. A.Z. Khan, B. Barkdoll, Int. J. Comput. Eng. Sci., 2, 3 453-467 (2001)

7. D.M. Hicks, P.D. Mason, Roughness Characteristics of New Zealand Rivers, New Zealand DSIR Marine and Freshwater Resources Survey, Wellington, NZ, (1991)

8. A.N. Papanicolaou, R. Hilldale, J. Eng. Mech., 128, 9 948-960 (2002)

9. J.C. Tannehill, D.A. Anderson, R.H. Pletcher, Computational Fluid Mechanics and Heat Transfer, 2nd Ed, Taylor \& Francis Publisher, Philadelphia, (1997)

10. A.J. Miller, B.L. Cluer, Fluvial Processes in Bedrock Channels, AGU Monograph 107, AGU, Washington, D.C., 61-104 (1998)

11. M. Elhakeem, A.N. Papanicolaou, International J. River Basin Management, 6, 1 63-77 (2008)

12. A.N. Papanicolaou, M. Elhakeem, and B. Wardman, Journal of Hydraulic Engineering, 137, 1 75-89 (2010)

13. D.W. Crowder, and P. Diplas, J. Hydrology, 230, 3 4 172-191 (2000)

14. R. J. Hardy, P.D. Bates, and M. G. Anderson, M. G. J. Hydrology, 216, 124-136 (1999)

15. G.E. Freeman, Solving the dilemma: To wave or to oscillate? Opposing formulations of the shallow water equations in river modeling, Ph.D. dissertation, Texas A\&M Univ., (1992)

16. D.R. Richards, Proc., 1990 National Conf. Hydraulics Engineering, H. H. Chang and J. C. Hill, eds., 2, ASCE, Reston, (1990)

17. L.R. Mays, Hydraulic Design Handbook, McGrawHill, New York, (1999) 